\title{
MULTIDIMENSIONAL POVERTY INDEX DI KECAMATAN KEDUNGKANDANG
}

\author{
Wara Indira Rukmi, Ismu Rini Dwi Ari, Anestia Lairatri Prabandari \\ Jurusan Perencanaan Wilayah dan Kota Fakultas Teknik Universitas Brawijaya \\ Jalan Mayjen Haryono 167 Malang 65145-Telp (0341)567886 \\ e-mail: waraindira_ub@yahoo.com
}

\begin{abstract}
ABSTRAK
Kemiskinan meruapakan permasalahan yang sering terjadi di negara-negara di dunia khususnya pada negara berkembang. Perhitungan nilai kemiskinan mangalami beberapa berubahan atau modifikasi sesuai dengan kondisi saat ini. Kondisi kemiskinan tidak lagi hanya dipandang sebagai keterbatasan seseorang dari sisi finansial (pendapatan), tetapi juga beberapa dimensi lainnya. Pengukuran kemiskinan menggunakan metode Multidimensional Poverty Index merupakan salah satu metode pengukuran kemiskinan yang memperhatikan 3 (tiga) dimensi antara lain pendidikan, kesehatan dan standar hidup. Penelitian ini berlokasi di Kecamatan Kedungkandang. Kecamatan Kedungkandang merpakan salah satu kecamatan di Kota Malang yang memiliki jumlah penerima beras miskin tertinggi yaitu sebesar 5260 KK miskin. Kecamatan Kedungkandang memiliki penduduk sebesar 1.888 .175 jiwa yang terbagi menjadi 12 kelurahan. Pengukuran kemiskinan menggunakan Multidimensional Poverty Index di Kecamatan Kedungkandang terbagi mejadi kategori sangat rendah. Kelurahan yang memiliki nilai MPI terendah yaitu Kelurahan Kotalama (0,01) dan Kelurahan Sawojajar (0,01) sedangkang Kelurahan yang memiliki nilai MPI tertnggi adalah Kelurahan Lesanpura (0,07) dan Kelurahan Wonokoyo (0,07). Semakin tinggi nilai MPI mengindikasikan daerah tersebut semakin miskin.
\end{abstract}

Kata Kunci : kemiskinan, perkotaan, multidimensional poverty index

\section{ABSTRACT}

Poverty is one problem that often occurs in countries in the world, especially in developing countries. The calculation of poverty values has changed or modified in accordance with the current conditions. The condition of poverty is not only seen as a person's limitations in terms of financial (income) but several other dimensions. Poverty measurement using the Multidimensional Poverty Index method is one method of measuring poverty which pays attention to 3 (three) dimensions such as education, health and living standards. This research is located in Kedungkandang District. Kedungkandang sub-district is one of the districts in Malang that has the highest number of poor rice recipients, amounting to 5260 poor households. Kedungkandang Subdistrict has a population of 1,888,175 people, divided into 12 villages. Poverty measurement using the Multidimensional Poverty Index in Kedungkandang District is divided into a very low category. The villages that have the lowest MPI values are Kotalama Village (0.01) and Sawojajar Village (0.01) while the villages that have the highest MPI values are Lesanpura Village (0.07) and Wonokoyo Village (0.07). The higher MPI value indicates the poorer the area.

Keywords: poverty, urban area, multidimensional poverty index

\section{PENDAHULUAN}

Sustainable Development Goals (SDGs) menjadi landasan utama untuk kegiatan pengentasan kemiskinan di Indonesia ini. Target tujuan pembangunan berkelanjutan dan prioritas pembangunan nasional yang mengacu pada SDGs dalam penelitian ini terkait pada beberapa program, yakni program penanggulangan kemiskinan, program Indonesia sehat, program Indonesia pintar, perlindungan anak, perempuan dan kelompok marjinal, ketahanan air, pembangunan daerah tertinggal dan program pemerataan pembangunan antar wilayah.

Kemiskinan merupakan kondisi dimana individu memiliki keterbatasan dalam pemenuhan kebutuhan dasar harian seperti sandang, pangan dan papan. Kemiskinan adalah permasalahan multidimensi dan setiap daerah memiliki cara sendiri untuk mengatasi, jadi sangatlah penting untuk mengidentifikasi penyebab terjadinya kemiskinan seperti korupsu, penddikan, politik dan keadaan natural geografi. Permasalah utama penyebab terjadinya kemiskinan perlu ditasi sehingga tidak adanya tali kemiskinan yang terjadi secara terus menerus (Alex, 2013). Paradigma pembangunan manusia memiliki evolusi yang menjadi dasar landasan teoritis berkembangkanya terori pengukuran kemiskinan secara multidimensi (melihat dari beberapa aspek dimensi) (Bidyadhar and Sanjay, 2015). Selama ini perhitungan nilai kemiskinan dilakukan dengan pendenkatan moneter sepertu garis kemsikinan atau melalu pendekatan konsumsi 
dasar, pendekatan tersebut dirasa hanya dapat memotret nilai keiskianna sebagian kecl dari begit besarnya permasalahan kemiskinan yang terjadi. UNDP menyebutkan bahwa memperluas penilaian atau engukurna kemiskinan secara multidimensi meruakan strategi awal dalam kerangka penanggulangan kemiskinan global (Budiantoro et al, 2013).

BPS mencatat pada tahun 2019 jumlah kemiskinan di Inonesia sebesar $9.41 \%$ dari total jumlah penduduk yang ada. Garis kemiskinan di Indonesia sebesar Rp. 425.250/kapita/bulan dengan engan komposisi Garis Kemiskinan Makanan sebesar Rp 313.232 (73,66 persen) dan Garis Kemiskinan Bukan Makanan sebesar Rp 112.018 (26,34\%). Pada Maret 2019, secara ratarata rumah tangga miskin di Indonesia memiliki 4,68 orang anggota rumah tangga. Dengan demikian, besarnya Garis Kemiskinan per rumah tangga mi skin secara rata-rata adalah sebesar Rp 1.990.170/rumah tangga miskin/bulan.

Berbagai strategi penanggulangan kemiskinan di wilayah Indonesia telah dilakukan sejak awal kemerdekaan Indonesia, seperti adanya program-program pembangunan yang berorientasi pada pengentasan kemiskinan dengan tujuan akhir untuk meningkatkan kesejahteraan masyarakat. Adanya upaya penanggulangan kemiskinan dapat memberikan dampak positif yakni penurunan angka kemiskinan, sebagaimana tercatat oleh Badan Pusat Statistik.

Salah satu wilayah perkotaan di Indonesia yang masih mengalami permasalahan kemiskinan adalah Kota Malang. Badan Pusat Statistik mencatat bahwa pada tahun 2016, terdapat 35,49 ribu penduduk miskin di Kota Malang. Kecamatan Kedungkandang merupakan salah satu kecamatan di Kota Malang yang memiliki penduduk miskin tertinggi.

\section{METODE PENELITIAN}

\section{Jenis Penelitian}

Jenis penelitian yang digunakan pada penelitian adalah kuantitatif. Penelititan kuantitatif merupakan penelitian yang menggunakan rancangan penelitian yang berdasarkan prosedur statistik atau dengan kuantifikasi pengukuran terhadap suatu variabel (Sugiyono, 2011).

\section{Pengumpulan Data dan Sampel}

Populasi yang digunakan pada penelitian ini adalah seluruh rumah pada Kecamatan Kedungkandang, Kota Malang. Sampel pada penelitian ini adalah rumah tangga yang diambil menggunakan rumus proporsional stratified random sampling dimana penelitian ini tidak dilakukan pada seluruh populasi, tapi terfokus pada target. Teknik pengambilan sampel dari populasi adalah dengan cara proporsional stratified random sampling dimana jumlah sampel dan responden yang akan diambil pada Kecamatan Kedungkandang tidak homogen dan populasi dikelompokkan ke dalam kelompok atau kategori yang disebut strata (Kumalaningsih, 2012). Strata pada penelitian ini terbagi kedalam kelurahan. Jumlah sampel pada penelitian ini berjumlah 276 rumah tangga yang tersebar kedalam 12 kelurahan yang ada.

\section{Multidimensional Poverty Index (MPI)}

Multidimensional Poverty Index (MPI) atau Indeks Kemiskinan Multidimensi merupakan alat ukur kemiskinan berupa derajat keparahan kemiskinan dalam berbagai dimensi yang mempengaruhi kapabilitas manusia (UNDP, 2016). Perhitungan MPI dihitung menggunakan bobot tertimbang dari dimensi dan indikator. Bobot dari dimensi ditimbang sama yaitu $1 / 3$ masing-masing dimensi dan masing-masing indikator dalam dimensi juga ditimbang sama.

Bobot indikator kesehatan yang terdiri dari dua indikator dinilai sebesar $1 / 6$, bobot pendidikan yang terdiri dari dua indikator dinilai $1 / 6$ dan bobot kualitas hidup yang terdiri dari enam indikator dinilai 1/18. Metode Multidimensional Poverty Index (MP) memliki 3 dimensi yaitu dimensi kesehatan, dimensi pendidikan dan dimensi standar hidup. beriut merupakan dimensi dan langkah perhitungan MPI.

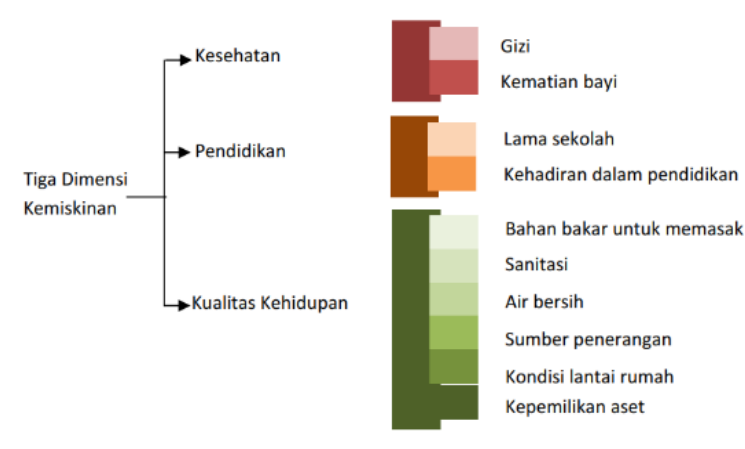

Gambar 1. Dimensi MPI

Sumber : Budiantoro et al,2013

1) Setiap orang akan memberikan deprivasi dalam rumah tangga pada setiap 10 komponen indikator 
Tabel 1. Dimensi, Indikator, dan Bobot MPI

\begin{tabular}{|c|c|c|c|}
\hline Dimensi & Indikator & $\begin{array}{l}\text { Terdeprivasi } \\
\text { jika... }\end{array}$ & Bobot \\
\hline \multirow{2}{*}{$\begin{array}{l}\text { Pendidikan } \\
\text { (Education) }\end{array}$} & $\begin{array}{l}\text { Lama } \\
\text { sekolah atau } \\
\text { tingkat } \\
\text { pendidikan } \\
\text { terakhir } \\
\text { (school } \\
\text { attainment) }\end{array}$ & $\begin{array}{l}\text { Tidak terdapat } \\
\text { anggota rumah } \\
\text { tangga yang } \\
\text { menempuh } \\
\text { pendidikan } \\
\text { minimal }^{(1)}\end{array}$ & $16,7 \%$ \\
\hline & $\begin{array}{l}\text { Kehadiran/ } \\
\text { partisipasi } \\
\text { dalam } \\
\text { sekolah } \\
\text { (attadence } \\
\text { of school) }\end{array}$ & $\begin{array}{l}\text { Terdapat anak } \\
\text { usia pelajar }{ }^{(2)} \\
\text { yang tidak } \\
\text { sekolah }\end{array}$ & $16,7 \%$ \\
\hline \multirow{2}{*}{$\begin{array}{l}\text { Kesehatan } \\
\text { (Health) }\end{array}$} & $\begin{array}{l}\text { Gizi } \\
\text { (nutrition) }\end{array}$ & $\begin{array}{l}\text { Terdapat riwayat } \\
\text { anak yang } \\
\text { meninggal dalam } \\
\text { kurun waktu } 5 \\
\text { tahun terakhir }\end{array}$ & $16,7 \%$ \\
\hline & $\begin{array}{l}\text { Kematian } \\
\text { anak (child } \\
\text { mortality) }\end{array}$ & $\begin{array}{l}\text { Terdapat anggota } \\
\text { keluarga (dewasa } \\
\text { atau anak) yang } \\
\text { mengalami } \\
\text { malnutrisi }{ }^{(3)}\end{array}$ & $16,7 \%$ \\
\hline \multirow{6}{*}{$\begin{array}{l}\text { Standar } \\
\text { Hidup } \\
\text { (Standard of } \\
\text { Living) }\end{array}$} & $\begin{array}{l}\text { Air Bersih } \\
\text { (Drinking } \\
\text { Water) }\end{array}$ & $\begin{array}{l}\text { Rumah tangga } \\
\text { tidak memiliki } \\
\text { akses air bersih } \\
\text { layak/sumber air } \\
\text { bersih layak }\end{array}$ & $5,6 \%$ \\
\hline & $\begin{array}{l}\text { Sanitasi } \\
\text { (Sanitation) }\end{array}$ & $\begin{array}{l}\text { Rumah tangga } \\
\text { memiliki jenis } \\
\text { sanitasi yang tidak } \\
\text { layak atau jenis } \\
\text { sanitasi layak } \\
\text { namun berbagi / } \\
\text { dipakai bersama } \\
\text { dengan rumah } \\
\text { tangga lainnya }\end{array}$ & $5,6 \%$ \\
\hline & $\begin{array}{l}\text { Listrik } \\
\text { (Electricity) }\end{array}$ & $\begin{array}{l}\text { Rumah tangga } \\
\text { tidak memiliki } \\
\text { akses listrik }\end{array}$ & $5,6 \%$ \\
\hline & $\begin{array}{l}\text { Jenis Lantai } \\
\text { (Floor) }\end{array}$ & $\begin{array}{l}\text { Rumah tangga } \\
\text { yang memiliki } \\
\text { lantai dari pasir, } \\
\text { tanah, atau } \\
\text { kotoran }\end{array}$ & $5,6 \%$ \\
\hline & $\begin{array}{l}\text { Bahan } \\
\text { Bakar untuk } \\
\text { memasak } \\
\text { (Cooking } \\
\text { Fuel) }\end{array}$ & $\begin{array}{l}\text { Rumah tangga } \\
\text { yang } \\
\text { menggunakan } \\
\text { arang, briket, } \\
\text { kayu bakar, } \\
\text { minyak tanah. }\end{array}$ & $5,6 \%$ \\
\hline & $\begin{array}{l}\text { Kepemilika } \\
\text { n Aset } \\
\text { (Assets) }\end{array}$ & $\begin{array}{l}\text { Rumah tangga } \\
\text { yang tidak } \\
\text { memiliki minimal } \\
\text { salah satu dari } \\
\text { aset }\end{array}$ & $5,6 \%$ \\
\hline
\end{tabular}

Sumber: Technical Notes HDR 2016:9

2) Skor deprivasi dari masing-masing indikator dijumlahkan dan menghasilkan skor deprivasi rumah tangga $\left(\mathrm{c}_{\mathrm{i}}\right)$

$$
\mathrm{ci}=\mathrm{W}_{\mathrm{i}} \mathrm{I}_{1}+\mathrm{W}_{\mathrm{i}} \mathrm{I}_{2}+\ldots .+\mathrm{WnIn}
$$

Keterangan:

$\mathrm{I}_{1}$ adalah sama dengan 1 jika seseorang dalam rumah tangga terdeprivasi dalam indikator $\mathrm{i}$, dan I1 adalah sama dengan 0 jika tidak.

$\mathrm{W}_{\mathrm{i}}$ adalah bobot dari indikator $\mathrm{i}$

Headcount ratio $(\mathrm{H})$ atau angka kemiskinan multidimensi adalah proporsi dari orang miskin multidimensi dalam populasi.

$$
\mathrm{H}=\frac{q}{n}
$$

\section{Keterangan:}

q adalah jumlah orang yang dikategorikan miskin secara multidimensional (skor deprivasi $\geq 33 \%$ ) $\mathrm{n}$ adalah total populasi.

3) Intensity of Poverty (A) atau intensitas kemiskinan merupakan persentase rata-rata deprivasi/kekurangan rumah tangga pada saat bersamaan yang mencerminkan proporsi komponen indikator terbobot dimana rata-rata orang miskin terdeprivasi.

$$
\mathrm{A}=\frac{\sum_{i}^{q} c_{i}}{q}
$$

Keterangan:

q adalah jumlah individu yang dikategorikan miskin secara multidimensional

$\mathrm{c}_{\mathrm{i}}$ adalah skor deprivasi dari rumah tangga miskin

4) Perhitungan nilai MPI

$$
\text { MPI }=\mathrm{H} \times \mathrm{A}
$$

Keterangan:

$\mathrm{H}$ adalah Headcount Ratio

A adalah Intensity of Poverty

\section{HASIL DAN PEMBAHASAN}

\section{Gambaran Kecamatan Kedungkandang}

Kecamatan Kedungkandang terletak antara 112036'14" - 112040'42" Bujur Timur dan 077036'38" - 008001'57" Lintang Selatan. Kecamatan Kedungkandang terletak pada ketinggian 440 - 460 meter diatas permukaan laut (dpl). Jumlah penduduk Kecamatan Kedungkandang sebesar 1.888.175 jiwa yang tersebar kedalam 12 kelurahan. 


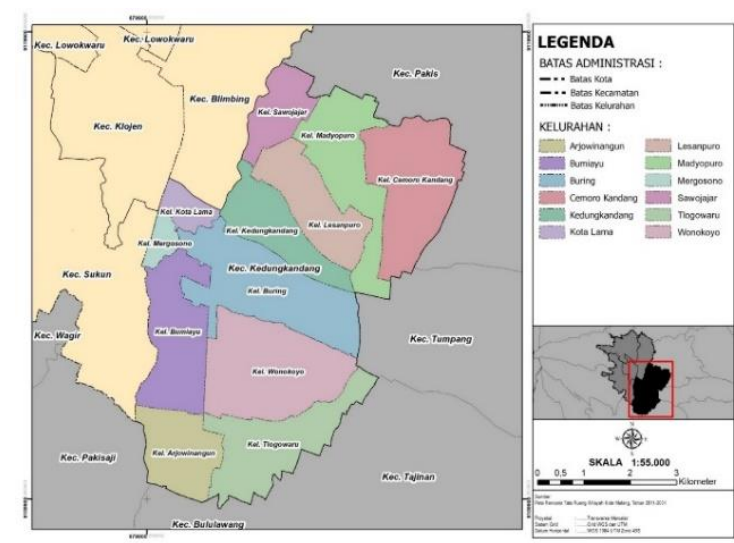

Gambar 2. Peta Administrasi Kecamatan Kedungkandang

\section{1) Penduduk Penerima Beras Miskin}

Data kemiskinan Kecamatan Kedungkang diketahui jumlah penerima terbanyak yaitu pada Kelurahan Kota Lama yaitu sebanyak 816 KK dan kelurahan yang memiliki jumlah kk miskin terendah yaitu 167 KK yaitu pada Kelurahan Arjowinangun. Persebaran jumlah kk miskin di Kecamatan Kedungkandang dapat dilihat pada tabel berkut.

Tabel 2. Persebaran KK miskin berdasarkan Kelurahan (KK penerima beras miskin)

\begin{tabular}{lc}
\hline \multicolumn{1}{c}{ Kelurahan } & Jumlah KK miskin \\
\hline Arjowinangun & 167 \\
\hline Tlogowaru & 179 \\
\hline Wonokoyo & 281 \\
\hline Bumiayu & 466 \\
\hline Buring & 741 \\
\hline Mergosono & 620 \\
\hline Kotalama & 816 \\
\hline Kedungkandang & 287 \\
\hline Sawojajar & 333 \\
\hline Madyopuro & 394 \\
\hline Lesanpuro & 621 \\
\hline Cemorokandang & 355 \\
\hline
\end{tabular}

2) Distribusi Pendapatan (Indeks Gini)

Distribusi pendapatan yang baik jika sebuah wilayah memiliki pemerataan pendapatan sehingga tidak ada masyarakat yang merasakan ketimpangan atau ketidakmerataan pendapatan. Distribusi pendapatan dapat dihitung menggunakan indeks gini. Indeks gini memiliki rentang 0 hingga 1 , dimana nilai mendekati 1 menandakan wilayah tersebut memiliki ketimpangan pendapatan yang tinggi. Berikut ini merupakan perhitungan distribusi pendapat pada setiap kelurahan di Kecamatan Kedungkandang.

\section{Tabel 3. Indeks Gini Kecamatan Kedungkandang}

\begin{tabular}{lc}
\hline Kelurahan & Nilai Indeks Gini \\
\hline Arjowinangun & 0,26 \\
Tlogowaru & 0,15 \\
Wonokoyo & 0,24 \\
Bumiayu & 0,27 \\
Buring & 0,23 \\
Mergosono & 0,30 \\
Kotalama & 0,24 \\
Kedungkandang & 0,31 \\
Sawojajar & 0,22 \\
Madyopuro & 0,32 \\
Lesanpuro & 0,21 \\
Cemorokandang & 0,3 \\
\hline
\end{tabular}

\section{3) Hasil Pengukuran Dimensi \\ Multidimensional Poverty Index}

Pengukuran tingkat kemiskinan di Kecamatan kedungkandang dapat dilakukan melalui indikator kemiskinan yaitu Multidimensional Poverty Index. Berikut merupakan hasil perhitungan Multidimensional Poverty Index.

a. Dimensi Pendidikan

Dimensi Pendidikan pada penelitian ini adalah menggunakan data tingkat pendidikan terkahir dan partisipasi masyarakat terhadap pendidikan yang dinilai berdasarkan keberadaan anak usia sekolah (6-23 tahun) yang hadir/turut berpartisipasi dalam pendidikan sesuai usianya atau telah selesai menempuh pendidikan minimal (12 tahun). Berikut merupakan gambaran dimensi pendidikan pada Kecamatan Kedungkandang berdasarkan hasil survei.

Tabel 4. Dimensi Pendidikan Masyarakat Kecamatan Kedungkandang Berdasarkan Hasil Survei

\begin{tabular}{lccc}
\hline Kelurahan & $\begin{array}{c}\text { Mespon } \\
\text {-den }\end{array}$ & $\begin{array}{c}\text { Mangarakat } \\
\text { lulus } \\
\text { Pendidikan } \\
\text { Minimal SMA }\end{array}$ & $\begin{array}{c}\text { Tingkat } \\
\text { Partisipasi }\end{array}$ \\
\hline Arjowinangu & 15 & $40 \%$ & $0 \%$ \\
\hline Tlogowaru & 9 & $44 \%$ & $0 \%$ \\
\hline Wonokoyo & 9 & $22 \%$ & $0 \%$ \\
\hline Bumiayu & 25 & $32 \%$ & $0 \%$ \\
\hline Buring & 18 & $28 \%$ & $0 \%$ \\
\hline Mergosono & 26 & $19 \%$ & $0 \%$ \\
\hline Kotalama & 45 & $29 \%$ & $0 \%$ \\
\hline Kedungkandang & 15 & $27 \%$ & $0 \%$ \\
\hline Sawojajar & 38 & $29 \%$ & $0 \%$ \\
\hline Madyopuro & 29 & $28 \%$ & $0 \%$ \\
\hline Lesanpuro & 28 & $11 \%$ & $0 \%$ \\
\hline Cemorokandang & 19 & $26 \%$ & $0 \%$ \\
\hline
\end{tabular}

Berdasarkan Tabel 4 diketahui bahwa jumlah masyarakat yang tidak lulus pendidikan 
minimal SMA tertinggi berada di Kelurahan Tlogowaruu (44\%) dan terendah pada Kelurahan Lesanpura $(11 \%)$. Sedangkan untuk parameter tingkat partisapasi seluruh kelurahan memiliki nilai tingkat partisipasi $0 \%$ yang berarti tidak ada anak usia sekolah yang tidak bersekolah.

b. Dimesi Kesehatan

Dimensi kesehatan pada penelitian ini mencakup 2 indikator yaitu angka kematian bayi dan bayi malnutrisi. Berikut merupakan dimensi kesehatan di Kecamatan Kedungkandang.

Tabel 5. Dimensi Kesehatan Kecamatan Kedungkandang Berdasarkan Hasil Hasil Survei

\begin{tabular}{lccc}
\hline Kelurahan & $\begin{array}{c}\text { Jumlah } \\
\text { Responden }\end{array}$ & $\begin{array}{c}\text { Julah } \\
\text { Balita } \\
\text { Malnut } \\
\text { risi }\end{array}$ & $\begin{array}{c}\text { Tingkat } \\
\text { Kematian } \\
\text { Bayi }\end{array}$ \\
\hline Arjowinangu & 15 & $0 \%$ & $0 \%$ \\
\hline Tlogowaru & 9 & $0 \%$ & $0 \%$ \\
\hline Wonokoyo & 9 & $0 \%$ & $0 \%$ \\
\hline Bumiayu & 25 & $0 \%$ & $0 \%$ \\
\hline Buring & 18 & $0 \%$ & $0 \%$ \\
\hline Mergosono & 26 & $0 \%$ & $0 \%$ \\
\hline Kotalama & 45 & $0 \%$ & $0 \%$ \\
\hline Kedungkandang & 15 & $0 \%$ & $0 \%$ \\
\hline Sawojajar & 38 & $0 \%$ & $0 \%$ \\
\hline Madyopuro & 29 & $0 \%$ & $0 \%$ \\
\hline Lesanpuro & 28 & $0 \%$ & $0 \%$ \\
\hline Cemorokandang & 19 & $0 \%$ & $0 \%$ \\
\hline
\end{tabular}

Berdasarkan hasil survei, diketahui bahwa di Kecamatan Kedungkandang tidak pernah terjadi kasus bayi meninggal atau bayi malnutrisi.

\section{c. Dimensi Standar Hidup}

Dimensi standar hidup dalam penelitian ini, menggunakan enam indikator untuk standar hidup, mencakup tiga standar indikator Millineum Development Goals (MDG) yang terkait dengan kesehatan dan standar hidup seperti akses air bersih, sanitasi, dan penggunaan bahan bakar memasak. Pembenaran untuk indikator ini adalah cukup disajikan dalam literatur MDG. Hal ini juga mencakup dua non MDG-indikator: listrik dan material lantai. Kedua indikator memberikan beberapa indikasi dasar dari kualitas perumahan untuk rumah tangga. Indikator akhir meliputi kepemilikan beberapa barangbarang yang menunjang akses informasi seperti telepon, radio, $\mathrm{TV}$, menunjang mobilitas seperti mobil, sepeda motor dan mwnunjang hidup seperti hewan ternak, kepemilikan lahan. Berikut ini merupakan hasil dari dimensi standar hidup.
Tabel 6. Standar Hidup Kecamatan Kedungkandang

\begin{tabular}{lccc}
\hline Kelurahan & $\begin{array}{c}\text { Sumber } \\
\text { Penerangan }\end{array}$ & $\begin{array}{c}\text { Akses } \\
\text { ke air } \\
\text { bersih }\end{array}$ & $\begin{array}{c}\text { Kondisi } \\
\text { Sanitasi }\end{array}$ \\
\hline Arjowinangu & 0 & 2 & 1 \\
Tlogowaru & 0 & 2 & 0 \\
Wonokoyo & 0 & 2 & 2 \\
Bumiayu & 0 & 2 & 0 \\
Buring & 0 & 2 & 2 \\
Mergosono & 0 & 2 & 2 \\
Kotalama & 0 & 2 & 2 \\
Kedungkandang & 0 & 2 & 2 \\
Sawojajar & 0 & 2 & 2 \\
Madyopuro & 0 & 2 & 2 \\
Lesanpuro & 0 & 1 & 1 \\
Cemorokandang & 0 & 2 & 1 \\
\hline
\end{tabular}

\section{Hasil Pengukuran Dimensi Multidimensional Poverty Index}

a. Headcount Ratio (H) dan Intensitas Kemiskinan (A)

Headcount Ratio (H) menunjukan persentase penduduk desa di Kecamatan Kedungkandnag yang hidup dalam rumah tangga miskin multidimensi dalam sebuah populasi. Intensitas Kemiskinan (A) memiliki pengertia persentase masnyarakat miskin yang terdeprivasi dari indikator terbobot. Berikut ni merupakan perhitungan Headcount Ratio $(\mathrm{H})$ dan Intensitas Kemiskinan (A) Kecamatan Kedungkandang.

Tabel 7. Headcount Ratio (H) dan Intensitas Kemiskinan (A)

\begin{tabular}{lcc}
\hline \multicolumn{1}{c}{ Desa } & $\begin{array}{c}\text { Headcount } \\
\text { Ratio }(\mathbf{H})\end{array}$ & $\begin{array}{c}\text { Intensitas } \\
\text { Kemiskinan } \\
\text { (A) }\end{array}$ \\
\hline Arjowinangu & 0,2 & 0,33 \\
\hline Tlogowaru & 0,15 & 0,33 \\
\hline Wonokoyo & 0,4 & 0,33 \\
\hline Bumiayu & 0,16 & 0,33 \\
\hline Buring & 0,15 & 0,33 \\
\hline Mergosono & 0,10 & 0,33 \\
\hline Kotalama & 0,03 & 0,33 \\
\hline Kedungkandang & 0,14 & 0,33 \\
\hline Sawojajar & 0,03 & 0,33 \\
\hline Madyopuro & 0,17 & 0,33 \\
\hline Lesanpuro & 0,21 & 0,33 \\
\hline Cemorokandang & 0,08 & 0,33 \\
\hline
\end{tabular}

Pada Tabel 7 diketahui nilai Headcount Ratio (H) dan Intensitas Kemiskinan (A) kecamatan Kedungkandang. Nilai Headcount tertinggi yaitu pada Kelurahan Wonokoyo yaitu sebesar 0,4 atau $4 \%$ dan nilai Headcount Ratio $(\mathrm{H})$ 
terendah yaitu pada Kelurahan Sawojajar dan Kelurahan Kotalama yaitu sebesar 0,03 atau 3\%.

\section{b. Kontribusi Deprivasi}

Hasil perhitungan kontribusi deprivasi dapat memberikan informasi persentase pengaruh dari masing-masing dimensi kepada kemiskinan multidimensi pada masing-masing desa. Berikut merupakan hasil perhitungan deprivasi kemiskinan pada masing-masing dimensi Kecamatan Kedungkandang.

Tabel 7. Kontribusi Deprivasi pada MasingMasing Dimensi

\begin{tabular}{|c|c|c|c|}
\hline Desa & $\begin{array}{l}\text { Pendidikan } \\
(\%)\end{array}$ & $\begin{array}{l}\text { Kesehatan } \\
(\%)\end{array}$ & $\begin{array}{c}\text { Standar } \\
\text { Hidup } \\
(\%)\end{array}$ \\
\hline Arjowinangu & 23 & 0 & 23 \\
\hline Tlogowaru & 50 & 0 & 50 \\
\hline Wonokoyo & 50 & 0 & 50 \\
\hline Bumiayu & 15 & 0 & 15 \\
\hline Buring & 19 & 0 & 19 \\
\hline Mergosono & 50 & 0 & 50 \\
\hline Kotalama & 50 & 0 & 50 \\
\hline Kedungkandang & 50 & 0 & 50 \\
\hline Sawojajar & 50 & 0 & 50 \\
\hline Madyopuro & 11 & 0 & 11 \\
\hline Lesanpuro & 10 & 0 & 10 \\
\hline Cemorokandang & 17 & 0 & 17 \\
\hline
\end{tabular}

Berdasarkan hasil perhitungan pada tabel diatas maka diketahui nilai dari setiap dimensi yang dihitung yaitu dimensi pendidikan, kesehatan dan dimensi standart hidup. Dimensi pendidikan memiliki rentang 10\% sampai dengan $50 \%$. Dimensi kesehatan pada wilayah penelitian memiliki nilai $0 \%$ pada setiap kelurahan yang berarti pada setiap kelurahan di Kecamatan Kedungkandang tidak terdapat bayi meningal atau malnutrisi. Dimensi standart hidup memiliki rentang nilai $10 \%$ sampai dengan $50 \%$.

\section{c. Hasil Perhitungan Multidimensional Poverty Index (MPI) \\ MPI memiliki klasifikasi dalam lima kelas} yaitu sangat rendah, rendah, sedang, tinggi, dan sangat tinggi. Berdasarkan MPI Research Team in Indonesia, 2015 klasifikasi tersebut adalah sangat tinggi apabila hasil perhitungan adalah >0,36; nilai tinggi apabila hasil perhitungan berada diantara 0,27-0,36, sedang apabila: 0,18-0,27, rendah jka hasil perhitungan menunjukan nilai 0,09-0,18, dan sangat rendah apabila hasil perhitungan menunjukan $<0,09$. Berikut merupakan hasil perhitungan MPI di Kecamatan Kedungkandang. Tabel perhitungan
Multidimensional Poverty Index (MPI) Kecamatan Kedungkandang

\section{Tabel 8. Hasil Perhitungan MPI Kecamatan} Kedungkandang

\begin{tabular}{lll}
\hline \multicolumn{1}{c}{ Desa } & MPI & Klasifikasi \\
\hline Arjowinangun & 0.06 & Sangat rendah \\
\hline Bumiayu & 0.05 & Sangat rendah \\
\hline Buring & 0.05 & Sangat rendah \\
\hline Cemorokandang & 0.02 & Sangat rendah \\
\hline Kedungkandang & 0.05 & Sangat rendah \\
\hline Kotalama & 0.01 & Sangat rendah \\
\hline Lesanpuro & 0.07 & Sangat rendah \\
\hline Madyopuro & 0.05 & Sangat rendah \\
\hline Mergosono & 0.03 & Sangat rendah \\
\hline Sawojajar & 0.01 & Sangat rendah \\
\hline Tlogowaru & 0.05 & Sangat rendah \\
\hline Wonokoyo & 0.07 & Sangat rendah \\
\hline
\end{tabular}

Hasil perhitungan Multidimensional Poverty Index (MPI) pada Kecamatan Kedungkang memiliki klasifikasi sangat rendah pada semua kelurahan yang diteliti. Nilai Multidimensional Poverty Index (MPI) tertinggi yaitu pada Kelurahan Wonokoyo sebesar 0,07 dan nilai Multidimensional Poverty Index (MPI) terendah berada pada Kelurahan Sawojajar dan Kelurahan Kotalama dengan nilai sebesar 0,01 .

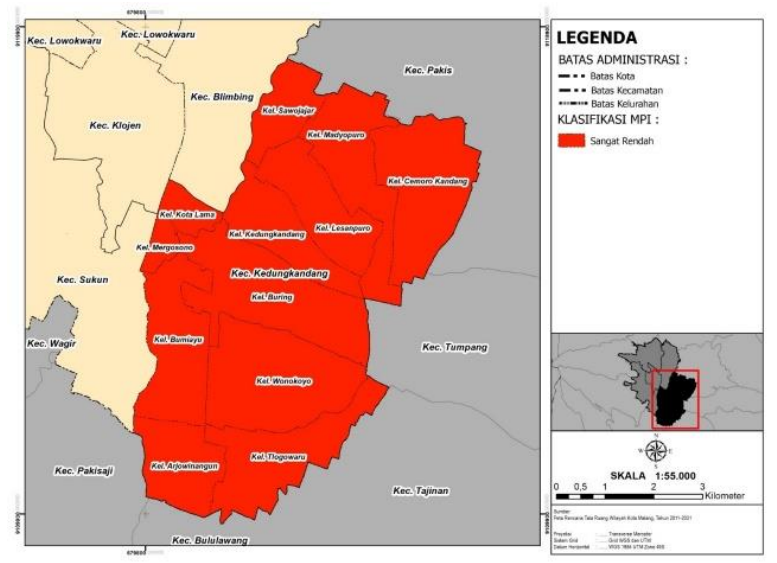

Gambar 3. Peta Klasifikasi Dimensi MPI Kecamatan Kedungkandang

\section{KESIMPULAN}

Kecamatan Kedungkandang merupakan salah satu kecamatan di Kota Mallang yang memiliki jumlah penduduk miskin terbanyak. Penenlitian ini bertujuan untuk melihat kemiskinan di Kecamaan Kedungkandang tidak hanya melalui sudaut pandang pendapatan namun dari 3 dimensi. Hasil pengukuran kemiskinan menggunakan metode Multidimensional Poverty Index (MPI) menunjukkan seluruh keluarahan di Kecamatan Kedungkandang memiliki nilai klasifikasi sangat rendah, hal tersebut menjukkan 
bahwa masyarakat berada di atas garis kemskinan yang telah diklasifikasikan oleh MPI.

\section{DAFTAR PUSTAKA}

Alex Hou Hong Ng, Abdul Ghani Farinda. Fock Kui Kan. Ai Ling Lim. Teo Ming Ting. 2013. Poverty: its Cause and Solutions. International Journal of Humanities and Social Sciences. Vol:7 No 8

Bidyadhar Dehury and Sanjay K Mohanty. 2015. Regional Estimates of Multidimensional Poverty in India. Economic E-journal

Budiantoro, Setyo. Victoria Fanggidae. Wido Saputra. Ah Maftuchan. Dwi Rani Puspa Artha. 2013. Multidimesional Poverty Index (MPI) : Konsep dan Pengukurannya. di Indonesia. Prakarsa Economic Policy Working Paper

BPS. 2019. Presentase Penduduk Miskin Maret 2019 sebesar 9,41 persen. Diakses online. https://www.bps.go.id/pressrelease/2019/0 7/15/1629/persentase-penduduk-miskinmaret-2019-sebesar-9-41-persen.html. 20 Maret 2019.

Kumalaningsih, Sri. (2012). Metodologi Penelitian Kupas Tuntas Mencapai Tujuan. Malang. Tim UB Press.

Sugiyono.(2011).Metode Penelitin Kuantittaif Kualitatif dan $R \& D$.Bandung.Alfabeta

United Nations Development Programme. 2016. Human Development Report 2016: Human Development for Everyone, Technical Notes. New York (USA): UN Plaza. 
